\title{
Prevalence and Risk Factors Associated With Otitis Media with Effusion in Children Visiting Tertiary Care Centre in Malaysia
}

Tikaram A, Chew YK, Zulkiflee AB, Chong AW, Prepageran N

Dept. of Otorhinolaryngology, Faculty of Medicine, University Malaya

\begin{abstract}
Introduction: The aim of this study is to determine the prevalence of otitis media with effusion (OME) in Malaysian children between three months to twelve years of age and to identify the risk factors associated with it. Materials and methods: This is a cross-sectional study consists of 153 children selected by stratified random sampling method. Parents of these children were interviewed with a structured questionnaire. Clinical examination, including otoscopic examination and tympanometry was performed for each child. Results: The prevalence of OME was $18.3 \%$. There was no statistical significant relationship between OME and gender, race, household size, attendance to daycare center, breast feeding, and exposure to passive smoking, allergy, and asthma. Conclusion: The prevalence of OME is $18.3 \%$ in Malaysian children between three months to twelve years of age. Frequency of AOM is a statistically significant factor to the development of OME later in life. The different risk factors associated with OME are still controversial.
\end{abstract}

KEYWORDS: Otitis media with effusion; risk factors; prevalence

\section{INTRODUCTION}

Otitis media with effusion (OME) is a middle ear disease characterized by presence of mucoid effusion in the middle ear without any signs of acute infection. ${ }^{1}$ This is a common clinical entity among the children. Since the disease is benign with an insidious onset, the diagnosis is usually delayed. The presence of fluid in the middle ear results in the impaired mobility of tympanic membrane and a conductive type of hearing loss. The complications and sequels of OME are an important public health problem. The patients will have impaired development of speech and language, poor school performance, tympanosclerosis, retraction pockets and psychosocial problems. 2, 3, 4

The pathogenesis of otitis media with effusion is still controversial. The causes such as Eustachian tube dysfunction, insufficient pneumatization of mastoid, craniofacial abnormalities, infections, immunodeficiency, and allergic agents are widely discussed. Various risk factors are implicated such as sex, race, premature delivery, passive smoking, allergy, asthma, family size, bottle feeding, socioeconomic status, cleft palate, adenoid hypertrophy, have been studied and are still controversial. ${ }^{1-4}$

Corresponding author:

Tikaram Adhikari

Dept of Otorhinolaryngology

Faculty of Medicine

University Malaya

59000, Kuala Lumpur.

Tel: 00603-79492062

Fax: 00603-79495563

Email: tikaram78@gmail.com
Although many studies on the prevalence and risk factors of OME have been done in the west, there are very few Malaysian studies. The risk factors in different studies have remained controversial. The aim of the study was to find the prevalence of OME and its associated risk factors in Malaysian children visiting tertiary care center and to identify the risk factors associated with OME.

\section{MATERIAL AND METHOD}

This is a cross-sectional study done in Klang Valley. The study population consists of children between three months to 12 years old who visited our tertiary medical care center for non otological problem such as in pediatric clinic or were accompanying parents visiting the hospitals. Children were randomly selected. Informed consent was obtained from the parents who agreed to be interviewed and have their children examined.

The structured questionnaire consists of two parts. The first part was to identify the risk factors associated with OME, and the second part was to determine the incidence of AOM and its relationship with OME. The risk factors as in Table I were assessed. For the incidence of $A O M$ and its relationship to OME the questions in Table II were asked.

Otoscopic examination and tympanometry were performed. The otoscopic finding was labeled as normal, evidence of scarring/thin ear drum, retracted ear drum or glue ear. The tympanometry was done using portable tympanometry. It was regarded as normal, type B and type C. In this study, we categorized the presence of abnormal otoscopic finding; type $\mathrm{B}$ tympanogram or both as OME. 
Table I: Risk factors of OME

Age
Single or both parents
No of siblings
Sex
Race
Daycare attendance
Breastfeeding
Exposed to passive smoking
Allergy
Asthma

The diagnosis of previous AOM was applied if the child had been diagnosed previously by medical personnels; or presence of previous history of painful purulent otorrhea. The various risk factor assessments were done using the SPSS 13 and the chi-square test was used to find the statistical significance. Statistical significant level is at $P$ value $<0.05$.

\section{RESULT}

A total of 153 children were examined. The age group varied between three months to 12 years with mean age of 5.99 . There were $83(54.2 \%)$ males and $70(45.8 \%)$ females. The population studied consists of Malay $84(54.9 \%)$, Indian 39(25.5\%), Chinese 25(16.3\%) and others 5(3.3\%).

There was no significant statistical relationship between $\mathrm{OME}$ and age, sex, race, single or both parent's presents, or number of siblings. The relationship between OME and visit to day-care centre, breast-feeding in childhood, passively exposed to smoking, allergy and asthma were also found to be statistically not significant. Table III shows the relationship between OME and risk factors.

With regards to the prevalence of AOM, 14 out of 153 were diagnosed as AOM in last three years. The children who were diagnosed with AOM had a higher incidence of OME, and this was statistically significant. The otalgia was present in 14 children. Four of the children had hearing problem. None of the children in this study had undergone any otological surgery. Table IV shows the relationship between AOM and $\mathrm{OME}$, analysed using chi-square test.

\section{DISCUSSION}

The prevalence of OME is rather variable, ranging from 1.3 to $31.3 \%$, which affect by the geographical area, races and studied population. The prevalence was $9.5 \%$ in Caucasians, ${ }^{5}$ 5.3\% in Chinese, ${ }^{6} 13.8 \%$ in Malaysian population. ${ }^{7}$ In the literature, the range of prevalence of OME is wide as the population studied, the countries, environmental factors and climatic factors were different. ${ }^{8}$ In our study, the overall prevalence of OME was $18.3 \%$. There were studies which Volume 11 Number 1 June 2012
Table II: Questions of relationship between AOM and OME

$$
\begin{aligned}
& \text { Any history of ear infection in last } \\
& 3 \text { years? } \\
& \text { Any history of pus / fluid discharge in } \\
& \text { last } 3 \text { years? } \\
& \text { Any hearing problem with child? } \\
& \text { Any earache in last } 3 \text { years? } \\
& \text { Any previous ear surgery done? }
\end{aligned}
$$

showed higher prevalence in male, $9,10,11$ owing to higher incidence of infectious disease in male. However, there were also studies which showed no gender preponderance. ${ }^{7}$ We did not find any significant difference in prevalence of OME between male and female in our data. In the West, there were studies which showed prevalence of OME to be higher in the whites than in blacks, ${ }^{12}$ Indians and Eskimos. ${ }^{9}$ Our result did not show any significant difference between different races, consist of Malays, Chinese, and Indians which is consistent with previous Malaysian studies. ${ }^{7}$

Gultekin et al. and Sassen showed that higher number of siblings in family increases the risk of OME. ${ }^{13,14}$ We did not find significant relationship between the number of siblings and the prevalence of OME. Children who attended daycare centres have increased risk of OME due to overcrowding and increased risk of cross infection in studies done earlier. ${ }^{1,13,15,16,17,18}$ However Sassen did not establish significant relation between OME and daycare stay after the confounding factors were eliminated ${ }^{14}$ Our study also did not identify any significant relationship between OME and attendance to daycare center. The confounding factor needs to be taken into consideration before a conclusion is reached.

Various studies done in the past support the protective role of breast-feeding and development of OME, 7,10,11,19 but other studies did not establish a significant relationship between the two. ${ }^{13,14,20,21}$ Breastfeeding may be protective in early years of life, but its protective action may not cover the older children. We could not establish any statistical relation between exposure to passive smoking and development of OME. This is parallel with the findings of previous studies done by Blackley and Blackley, ${ }^{4}$ and few others. ${ }^{7,14,21-23}$ There were a few other studies, which clearly demonstrated the relationship between the two. ${ }^{24-26}$ No significant association was also found between allergy and asthma in relation to OME, which was similar to previous studies done by Saim, ${ }^{7}$ but contrasted with the study done by E.Gultekin. ${ }^{13}$ Of the 153 children screened, ${ }^{14}$ were diagnosed as AOM in last three years. Alho et al. also showed that previous $A O M$ was the greatest risk factor for the development of OME. ${ }^{1} \mathrm{AOM}$ interferes with the Eustachian tube functions and leads to accumulation of fluid in the middle ear as found by Sassen. ${ }^{14}$ 
Table III: Relationship between OME and risk factors

\begin{tabular}{|c|c|c|c|}
\hline Risk factors & No of children & OME present & $P$ value \\
\hline \multicolumn{4}{|l|}{ Gender } \\
\hline Male & 83 & 14 & 0.677 \\
\hline Female & 70 & 14 & \\
\hline \multicolumn{4}{|l|}{ Race } \\
\hline Malay & 84 & 15 & \\
\hline Indian & 25 & 5 & 0.603 \\
\hline Chinese & 39 & 6 & \\
\hline Others & 5 & 2 & \\
\hline \multicolumn{4}{|l|}{ Parents } \\
\hline Single & 2 & 2 & 0.033 \\
\hline Both & 151 & 26 & \\
\hline \multicolumn{4}{|l|}{ No of children } \\
\hline 1 & 19 & 5 & \\
\hline 2 & 44 & 8 & \\
\hline 3 & 51 & 8 & 0.808 \\
\hline 4 & 29 & 6 & \\
\hline 5 & 5 & 1 & \\
\hline$>=6$ & 5 & 0 & \\
\hline \multicolumn{4}{|l|}{ Day care centre } \\
\hline Yes & 103 & 20 & 0.663 \\
\hline No & 50 & 8 & \\
\hline \multicolumn{4}{|c|}{$\begin{array}{l}\text { Exposed to passive } \\
\text { smoking }\end{array}$} \\
\hline Never & 87 & 12 & \\
\hline Rarely & 21 & 5 & 0.254 \\
\hline Frequently & 45 & 11 & \\
\hline \multicolumn{4}{|l|}{ Allergy } \\
\hline Yes & 24 & 7 & 0.153 \\
\hline No & 129 & 21 & \\
\hline \multicolumn{4}{|l|}{ Asthma } \\
\hline Yes & 30 & 7 & 0.436 \\
\hline No & 123 & 21 & \\
\hline
\end{tabular}

$P$ value obtained by chi-square test

Table IV: Relationship between AOM and OME.

\begin{tabular}{lccc}
\hline Problem & No of children & OME present & P value \\
\hline $\begin{array}{l}\text { Diagnosed with } \\
\text { ear infection }\end{array}$ & 14 & & \\
$\quad$ Yes & 139 & 10 & $<0.001$ \\
$\quad$ No & 18 & \\
$\begin{array}{l}\text { Hearing problem } \\
\text { Yes }\end{array}$ & 4 & 3 & 0.296 \\
$\quad$ No & 149 & 125 & \\
$\begin{array}{l}\text { Pus discharge } \\
\text { Yes }\end{array}$ & 14 & 4 & \\
$\quad$ No & 139 & 24 & \\
$\begin{array}{l}\text { Earache } \\
\quad \text { Yes }\end{array}$ & 17 & 11 & \\
$\quad$ No & 137 & 17 & \\
$\begin{array}{l}\text { Surgery to ear } \\
\text { Yes }\end{array}$ & 0 & 0.366 & \\
No & 153 & 28 & Not available \\
\hline
\end{tabular}

$P$ value obtained by chi square test 


\section{CONCLUSION}

The prevalence of OME in Malaysian children between three months to twelve years old is $18.3 \%$. Those children suffering from frequent episodes of $A O M$ have increased risk of development of OME later on. Other factors such as gender, race, household size, daycare center attendance, breastfeeding, exposure to smoking, allergy, asthma were not statistically significant.

\section{REFERENCES}

1. Alho OP, Oja H, Koivu M, Sorri M. Risk factors for chronic otitis media with effusion in infancy: Each acute otitis media episode induces a high but transient risk. Arch Otolaryngol Head Neck Surg 1995;121:839-43.

2. Aydogan B, Kiroglu M, Yilmaz M, et al. The role of food allergy in otitis media with effusion. Otolaryngol Head Neck Surg 2004; 130(6):747-50.

3. Bernstein JM. The role of IgE-mediated hypersensitivity in the development of otitis media with effusion. Otolaryngol Clin North Am 1992;25:197-211.

4. Blakley BW and Blakley J. Smoking and middle ear disease: are they related? A review article. Otolaryngol Head Neck Surg 1995;112(3):441-6.

5. Rushton $\mathrm{H}$, Yue V, Wormald PJ, Haselt CA. Prevalence of otitis media with effusion in multicultural schools in Hong Kong. J Laryngol Otol 1997;111: 804-806.

6. Tong MC, Yue V, Ku PK, Lo PS, Hasselt CA. Screening for otitis media with effusion to to measure its prevalence in Chinese children in Hong Kong. Ear Nose Throat J 2000;79: 626-30.

7. Saim A, Saim L, Saim S, Ruszymah B, Sani A. Prevalence of otitis media with effusion amongst pre-school children in Malaysia. Int J Pediatr Otorhinolaryngol 1997;41:21-8.

8. Okur E, Yildirim I, Kilic M, Guzelsoy S. Prevalence of otitis media with effusion among primary school children in Kahramanmaras, in Turkey. Int J Pediatr Otorhinolaryngol 2004;68:557-62.

9. Casselbrant ML, Brostoff LM, Cantekin EL, et al. Otitis media with effusion in preschool children. Laryngoscope 1985;95:428-36.

10. Paradise JL, Rockette HE, Colborn DK, et al. Otitis media in 2253 Pittsburgh-area infants: prevalence and risk factors during the first two years of life. Pediatrics 1997;99:318-33.

11. Teele D, Klein J, Rosner B. Epidemiology of otitis media during the first seven years of life in children in greater Boston: a prospective, cohort study. J Infect Dis 1989;160:83-94.

12. Griffith TE. Epidemiology of otitis media-an interracial study. Laryngoscope 1979;89:2230.
13. Gultekin E, Develioğlu ON, Yener M, Ozdemir I, Külekçi $M$. Prevalence and risk factors for persistent otitis media with effusion in primary school children in Istanbul, Turkey. Auris Nasus Larynx 2010;37:145-9.

14. Sassen M, Brand R, Grote J. Risk factors for otitis media with effusion in children 0 to 2 years of age. Am J Otolaryngol 1997;18:32430.

15. Rasmussen F. Protracted secretory otitis media. The impact of familial factors and day-care center attendance. Int J Pediatr Otorhinolaryngol 1993;26:29-37.

16. Stahlberg M, Ruuskanen O, Virolainen E. Risk factors for recurrent otitis media. Pediatr Infect Dis 1986;5:30-2.

17. Tainio VM, Savilahti E, Salmenpera L, at al. Risk factors for infantile recurrent otitis media: atopy but not type of feeding. Pediatr Res 1988;23:509-12.

18. Zielhuis G, Heinen HE, Rach GH, Van den Broek. Environmental risk factors for otitis media with effusion in preschool children. Scand J Prim Health Care 1989;7:33-8.

19. Schaefer O. Otitis media and bottle-feeding. An epidemiological study of infant feeding habits and incidence of recurrent and chronic middle ear disease in Canadian Eskimos. Can J Public Health 1971;62:478-89.

20. Harsten G, Prellner K, Heldrup J, Kalm O, Kornfalt R. Recurrent acute otitis media: a prospective study of children during the first three years of life. Acta Otolaryngol 1989;107: 111-9.

21. Tong $\mathrm{M}$, Yue V, Peter Ku, et al. Risk factors for otitis media with effusion in Chinese school children: a nested case-control study and review of the literature. Int J Pediatr Otorhinolaryngol 2006;70:213-9.

22. Lasisi A, Olaniyan F, Sufyan Muibi et al. Clinical and demographic risk factors associated with chronic suppurative otitis media. Int J Pediatr Otorhinolaryngol 2007;71:1549-54.

23. Rowe-Jones J, Brockbank M. Parental smoking and persistent otitis media with effusion in children. Int J Pediatr Otorhinolaryngol 1992;2419-24.

24. Iversen $M$, Birch L, Lundqvist $G$, Elbrond $\mathrm{O}$. Middle ear effusion in children and the indoor environment: An epidemiological study. Arch Environ Health 1985;40:74-9.

25. Stenström C, Ingvarsson L. Otitis-prone children and controls: a study of possible predisposing factors. 1. Heredity, family background and perinatal period. Acta Otolaryngol 1997;117:87-93.

26. Uhari M, Mäntysaari K, Niemela M. A metaanalytic review of the risk factors for acute otitis media. Clin Infect Dis 1996;22:1079-83. 